\title{
Inhibition of substrate synthesis as a strategy for glycolipid lysosomal storage disease therapy
}

\author{
F. M. Platt $^{1 *}$, M. Jeyakumar ${ }^{1}$, U. Andersson ${ }^{1}$, D. A. Priestman ${ }^{1}$, \\ R. A. DweK ${ }^{1}$ and T. D. Butters ${ }^{1}$
}

with clinical data contributed by T. M. COX ${ }^{2}$, R. H. LACHMANN ${ }^{2}$, C. Hollak ${ }^{3}$, J. M. F. G. Aerts ${ }^{3}$, S. Van Weely ${ }^{3}$, M. Hrebícek ${ }^{4}$, C. Moyses ${ }^{5}$, I. Gow ${ }^{5}$, D. ElSTEIN $^{6}$ and A. ZIMRAN 6

${ }^{1}$ Glycobiology Institute, Department of Biochemistry, University of Oxford, Oxford, $U K,{ }^{2}$ Department of Medicine, University of Cambridge, Addenbrooke's Hospital, Cambridge, UK, ${ }^{3}$ University of Amsterdam, Academic Medical Centre, Amsterdam, The Netherlands; ${ }^{4}$ Institute of Inherited Metabolic Disorders, Prague, Czech Republic; ${ }^{5}$ Oxford GlycoSciences, Abingdon, UK; ${ }^{6}$ Shaare Zedek Medical Center, Jerusalem, Israel

* Correspondence

\begin{abstract}
Summary: The glycosphingolipid (GSL) lysosomal storage diseases are caused by mutations in the genes encoding the glycohydrolases that catabolize GSLs within lysosomes. In these diseases the substrate for the defective enzyme accumulates in the lysosome and the stored GSL leads to cellular dysfunction and disease. The diseases frequently have a progressive neurodegenerative course. The therapeutic options for treating these diseases are relatively limited, and for the majority there are no effective therapies. The problem is further compounded by difficulties in delivering therapeutic agents to the brain. Most research effort to date has focused on strategies for augmenting enzyme levels to compensate for the underlying defect. These include bone marrow transplantation (BMT), enzyme replacement and gene therapy. An alternative strategy that we have been exploring is substrate deprivation. This approach aims to balance the rate of GSL synthesis with the impaired rate of GSL breakdown. The imino sugar $N$-butyldeoxynojirimycin (NB-DNJ) inhibits the first step in GSL biosynthesis and has been used to evaluate this approach. Studies in an asymptomatic mouse model of Tay-Sachs disease have shown that substrate deprivation prevents GSL storage in the CNS. In a severe neurodegenerative mouse model of Sandhoff disease, substrate deprivation delayed the onset of symptoms and disease progression and significantly increased life expectancy.
\end{abstract}


Combining NB-DNJ and BMT was found to be synergistic in the Sandhoff mouse model. A clinical trial in type I Gaucher disease has been undertaken and has shown beneficial effects. Efficacy was demonstrated on the basis of significant decreases in liver and spleen volumes, gradual but significant improvement in haematological parameters and disease activity markers, together with diminished GSL biosynthesis and storage as determined by independent biochemical assays. Further trials in type I Gaucher disease are in progress; studies are planned in patients with GSL storage in the CNS.

\section{GLYCOSPHINGOLIPID STORAGE DISEASES}

Glycosphingolipid (GSL) storage diseases are a family of severe, progressive disorders in which GSL species are stored in the lysosome (Figure 1) (Neufeld 1991). They have a collective incidence of 1:18000 live births and are the most frequent cause of paediatric neurodegenerative disease (Meikle et al 1999). The diseases result from the inheritance of mutations in genes that encode acid hydrolases or their protein cofactors, which participate in the sequential removal of monosaccharide units

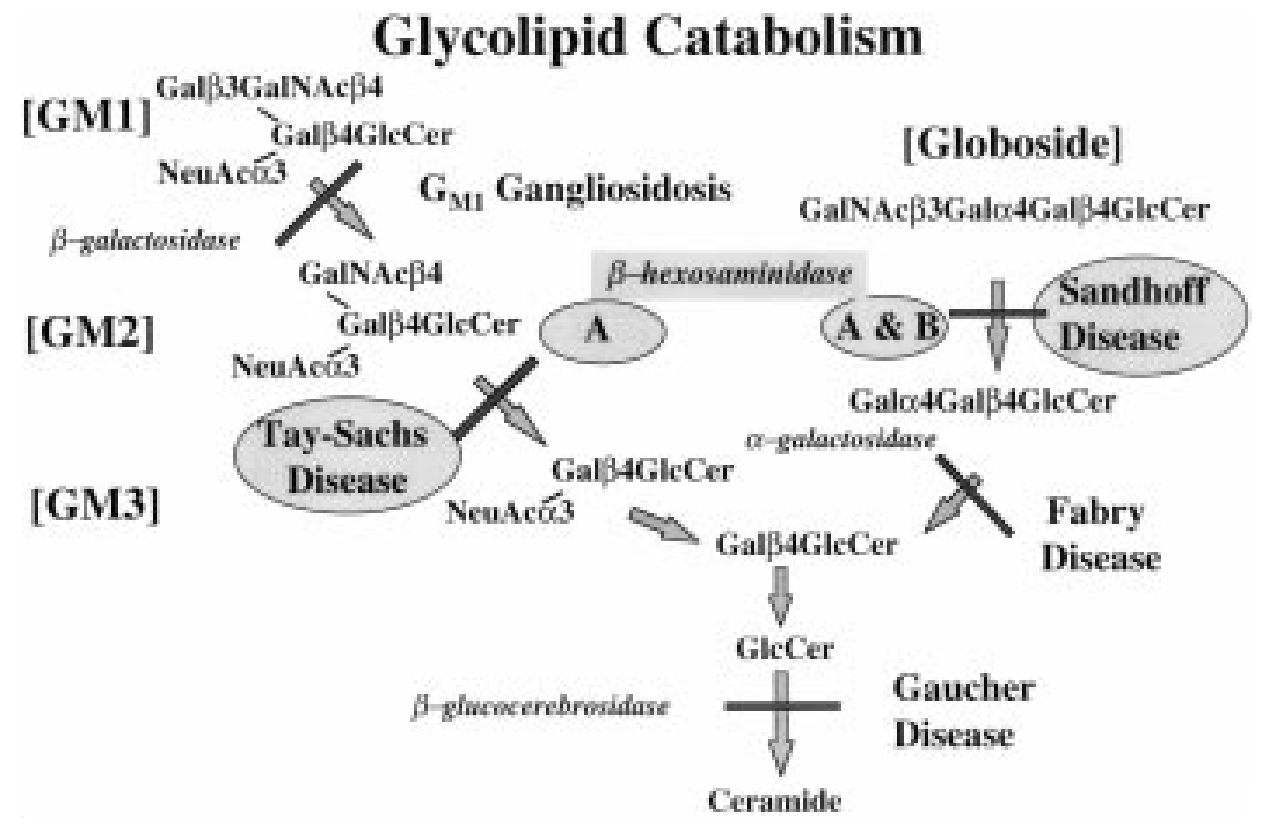

Figure 1 Summary of glycosphingolipid catabolism highlighting the enzyme deficiencies and resulting diseases. The GM2-gangliosidoses Tay-Sachs and Sandhoff diseases are emphasized because substrate deprivation therapy has been evaluated in mouse models of these two disorders 
from GSLs in the lysosome (Neufeld 1991). The clinical presentation of the disease varies depending on the specific gene defect and the GSL substrate that is stored. Since there is abundant expression of multiple GSL species in the CNS, particularly gangliosides, neurological features are prominent in the glycosphingolipidoses (Walkley 1998).

\section{THERAPEUTIC OPPORTUNITIES IN GSL STORAGE DISEASE}

There are several potential approaches that can be adopted for the treatment of GSL storage diseases. Many of these strategies would be predicted to be mutually complementary or synergistic. Since these diseases are due to the inheritance of defects in the genes encoding catabolic enzymes of the lysosome, introducing a functional gene should correct the problem. In common with other human monogenic diseases, this is an approach that holds enormous promise for those afflicted with these devastating diseases (Peng, 1999; Romano et al 1999). There are currently major technical difficulties that mean that gene therapy is still at an experimental stage for these and other diseases (Marshall, 1999; SoRelle, 2000). As the majority of GSL storage disorders involve GSL storage in the CNS, delivery to the brain is a prerequisite and constitutes a formidable challenge in terms of safety and efficacy of gene delivery and expression. Small increments in lysosomal enzyme activity may be crucial in preventing or reversing the manifestations of these diseases; effective gene therapy would be predicted to be an achievable goal in many lysosomal storage diseases.

An alternative approach, which is currently established for type I Gaucher disease (and very recently considerable progress has been made towards enzyme therapy for Fabry disease (Eng et al 2000) and Pompe disease (van den Hout et al 2001), is to infuse the patient with fully functional enzyme glycoforms that are taken up by cells in target tissues (e.g. mannose-terminated glucocerebrosidase for Gaucher disease or mannose 6-phosphate containing $\alpha$-glucosidase for Pompe disease). Because the passage of enzyme into the CNS is restricted by the blood-brain barrier, enzyme replacement therapy has limited efficacy in the neuronopathic variants, although the systemic manifestations of disease improve (Erikson et al 1997). An alternative approach to the development of novel treatments is to unravel the precise cellular events that take place following storage of GSLs to identify downstream intervention points. This strategy has the potential to identify targets for the action of small molecules and it is conceivable that currently used prescription drugs might have a therapeutic action in the GSL storage disease if a better understanding of their molecular pathogenesis was available. Understanding pathogenetic mechanisms has become a more realistic goal through the recent generation of mouse models of these diseases, which are amenable to detailed study and experimental manipulation (Suzuki and Mansson, 1998; Suzuki and Proia, 1998). In addition, the development of methods to investigate the gene expression profile of disease tissue using cDNA subtraction procedures or cDNA microarray 'chips' offers the possibility of establishing the pathological link between GSL storage and the protean manifestations of the glycosphingolipidoses (Moran et al 2000). 
There are also cell-based therapies such as bone marrow transplantation (BMT) (which will replace haematopoietic cells with wild-type cells secreting wild-type enzyme) (Erikson et al 1990; Ringden et al 1995). The limitation here is whether the lysosomal protein in question is naturally highly secreted, for recapture by neighbouring cells. Also, the amount of brain reconstitution with bone marrow-derived microglial cells is small and this may limit the amount of functional enzyme available to cells of the CNS (Krivit et al 1995). To date, although BMT has been useful for some of these diseases, the risks associated with the procedure itself and the requirement for HLA-matched donors severely limits its clinical application.

New emerging cell-based therapies involve injection of neuronal stem cells into the brain both to serve as a source of wild-type enzyme and also to replace dead or dying cells (Svendsen et al 1999; Vescovi and Snyder 1999). This experimental approach has implications for all neurodegenerative diseases, including the GSL storage diseases (Chavany and Jendoubi 1998). Neuronal stem cell therapy remains experimental at the present time, but the availability of authentic mouse models for GSL storage diseases will facilitate the evaluation of this promising approach.

The other therapeutic option is to decrease the synthesis of the stored substrate using enzyme inhibitors. This has been termed substrate deprivation or substrate reduction therapy. This approach was first suggested by Radin and colleagues (Inokuchi and Radin 1987; Radin, 1996). The principle is very simple. If a GSL species cannot be completely degraded as a result of the inherited enzyme deficiency, the biosynthesis of fewer GSL molecules will reduce the influx of GSLs into the lysosome, allowing all molecules to be catabolized. The aim is to balance synthesis with the impaired rate of degradation. If this could be achieved, the disease process resulting from GSL storage would be arrested. If complete balance cannot be achieved, then the disease will be converted into a less severe form with a slower rate of progression. There are three major advantages to this approach; first, an oral drug could be used; second, a drug that penetrates the CNS could be utilized; and third, if an early step in the GSL biosynthetic pathway is targeted then one drug could potentially treat a family of GSL storage diseases, without the need for disease-specific intervention. Since the number of individuals with any specific GSL storage disease may be small, economic considerations related to the development of disease-specific therapy mean it is unlikely to gain pharmaceutical backing or that it will be prohibitively expensive if commercialized. However, if a family of several diseases with a relatively high collective incidence can be treated with a single drug, this then may become a viable commercial proposition. Small-molecule drugs will be cheaper than protein-based therapeutics and therefore more likely to be accessible to patients than will expensive enzyme-replacement therapy. Currently, the great majority of type I Gaucher patients treated with enzyme replacement live in affluent countries.

\section{IMINO SUGAR INHIBITORS OF GSL BIOSYNTHESIS}

In 1993 it was discovered that the $N$-alkylated imino sugar $N$-butyldeoxynojirimycin (NB-DNJ) (Figure 2) inhibited the ceramide-specific glucosyltransferase (GlcT-1, 
<smiles>CCCCN1C[C@H](O)[C@@H](O)[C@H](O)[C@H]1CO</smiles>

NB-DNJ<smiles>CCCCN1C[C@H](O)[C@@H](O)[C@H](O)[C@H]1CO</smiles>

NB-DGJ

Figure 2 Structures of the imino sugars NB-DNJ (glucose analogue, OGT-918) and NB-DGJ (galactose analogue)

glucosylceramide synthase, UDP-glucose- $N$-acylsphingosine D-glucosyltransferase; EC 2.4.1.80) that catalyses the first step in the GSL biosynthetic pathway (Figure 3) (Platt et al 1994a). The GlcT-1 inhibitory activity is critically dependent on a minimal $N$-alkyl chain length of three carbons (Platt and Butters, 1995; Platt et al 1994a). This compound also inhibits the $N$-glycan processing enzymes $\alpha$-glucosidases I and II, which are glucohydrolases that reside in the endoplasmic reticulum (Platt et al 1992). This compound had been developed as an antiviral compound by Monsanto in the 1980s and so had been through extensive preclinical and clinical testing (Fischl et al 1994). It is orally available and very stable over a range of ambient temperatures and storage conditions (Platt and Butters, 1998). When evaluated as an anti-HIV agent in man the compound failed to show sufficient efficacy owing to the difficulty in efficiently reaching the endoplasmic reticulum (ER) $\alpha$-glucosidase enzyme that was the biochemical target (Fischl et al 1994). Oral dosing to obtain a sufficiently high serum concentration of the drug was the limiting factor. If dose was escalated to try to increase ER glucosidase inhibition, the oral dose required caused extensive inhibition of GI tract disaccharidases and resulted in osmotic diarrhoea. Patient compliance was poor because of GI tract distress, which was induced by high compound dosing (Fischl et al 1994).

\section{PRECLINICAL EVALUATION OF SUBSTRATE REDUCTION THERAPY}

The discovery of the novel activity of NB-DNJ against the key enzyme in the GSL biosynthetic pathway (GlcT-1) (Figure 3) coincided with the generation by Proia and colleagues and Gravel and colleagues of knockout mouse models of Tay-Sachs (TS) and Sandhoff (SH) diseases (Phaneuf et al 1996; Sango et al 1995; Taniike et al 1995; Yamanaka et al 1994). NB-DNJ was therefore evaluated in these mouse models (Sango et al 1995) to answer two critical questions: (a) would sufficient NB-DNJ cross the blood-brain barrier to slow storage in the asymptomatic TS mouse; and (b) in a symptomatic neurodegenerative mouse model (SH), would the disease process be significantly slowed by NB-DNJ therapy? 

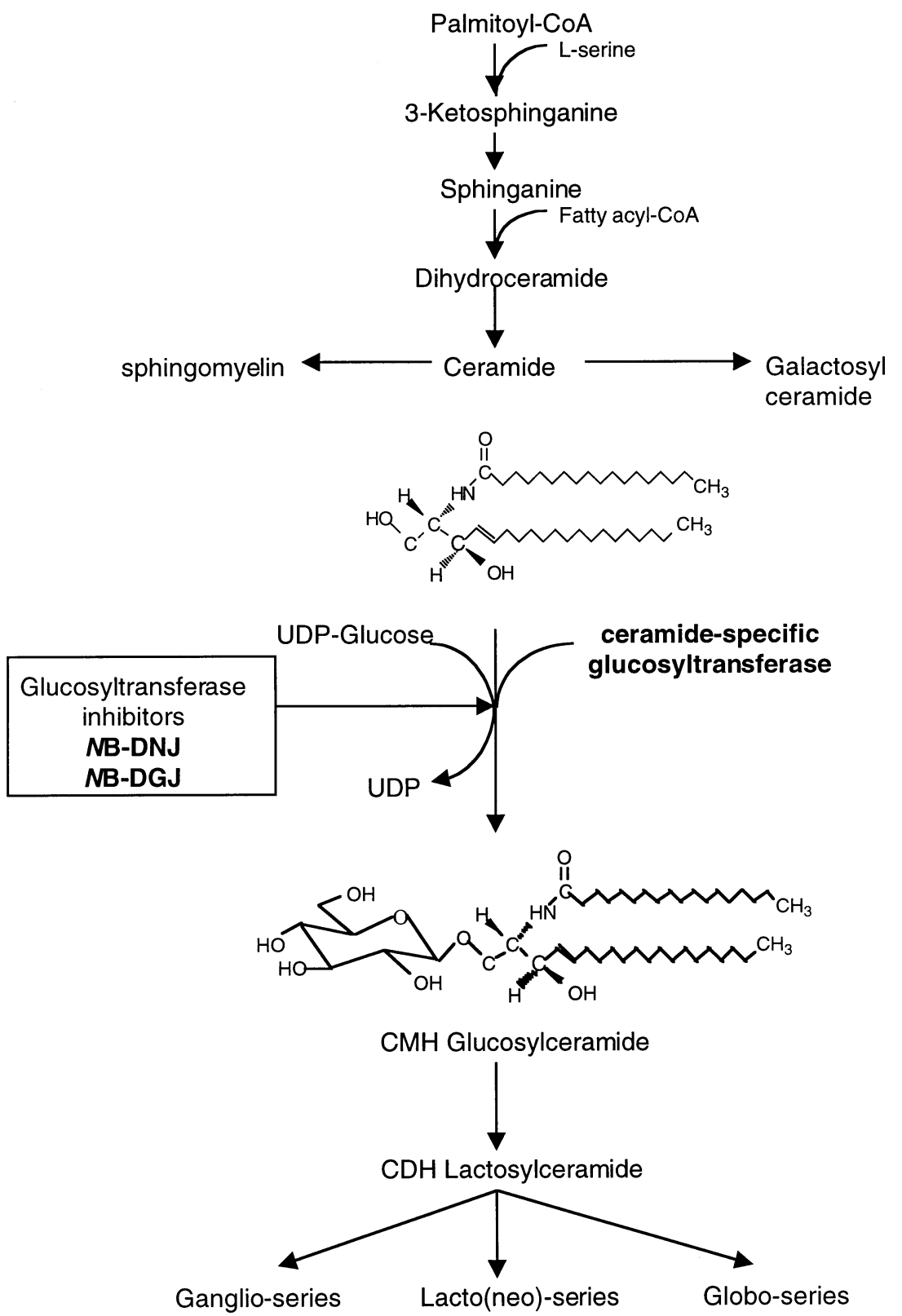

\section{Glycosphingolipids (GSL)}

Figure 3 Summary of glycosphingolipid biosynthesis highlighting the glucosyltransferase-catalysed biosynthesis of GlcCer, which is the step in the pathway inhibited by NB-DNJ and NB-DGJ 


\section{MOUSE MODEL OF TAY-SACHS DISEASE}

In the mouse model of Tay-Sachs disease (generated by the targeted disruption of the mouse Hexa gene), the mice store GM2 ganglioside in a progressive fashion, but the levels never exceed the threshold required to illicit neurodegeneration (Taniike et al 1995; Yamanaka et al 1994). This is because in mice (but not in humans) a lysosomal sialidase is sufficiently abundant or active to convert GM2 to GA2, which can then be catabolized by the hexosaminidase B isoenzyme, which is unaffected by the Hexa knockout (Sango et al 1995).

To evaluate substrate deprivation in the Tay-Sachs mouse model, mice were reared on food containing NB-DNJ (Platt et al 1997a). The pharmacokinetics of NB-DNJ are two orders of magnitude poorer in mice than in humans. This necessitates higher dosing in mice to achieve serum levels $(5-50 \mu \mathrm{mol} / \mathrm{L})$ in the predicted therapeutic range (partial inhibition of GlcT-1) for the GSL storage disorders (Platt et al 1997a). The mice were monitored for 12 weeks; a reduction in stored GM2-ganglioside was observed in all animals from the NB-DNJ-treated group (50\% reduction in GM2- ganglioside in the brains of treated mice relative to the untreated controls). In GSL storage regions of the brain, the NB-DNJ-treated mice had fewer periodic acid-Schiff (PAS)-positive neurons (PAS detects the stored GM2) and the intensity of staining in each neuron was reduced relative to that in those of untreated age-matched controls (Platt et al 1997a). At the EM level, in storage neurons from untreated Tay-Sachs mouse brains, prominent regions of the cytoplasm contained large numbers of membranous cytoplasmic bodies (MCBs) containing stored GM2. In contrast, in the NB-DNJ-treated mice, storage neurons were scarce. When storage cells could be identified they contained MCBs that had greatly reduced electron density. NB-DNJ was therefore able to cross the blood-brain barrier to an extent that prevented storage (Platt et al 1997a).

The finding that GSL depletion can be achieved in the CNS is significant because all the GlcCer-based GSL storage diseases could potentially be treated with NB-DNJ (Platt and Butters, 1998). NB-DNJ does not, however, inhibit the galactosyltransferase that initiates the biosynthesis of galactosylceramide (GalCer)-based GSLs. This is significant because the synthesis of GalCer and sulphatide, which are important components of myelin, will not be affected by NB-DNJ treatment and therefore myelination and myelin stability should not be impaired (Platt et al 1997a). As a consequence, NB-DNJ would not be predicted to be effective in the treatment of Krabbe disease and metachromatic leukodystrophy, as both of these diseases involve the storage of GalCer-based GSLs (GalCer and sulphatide, respectively) (Neufeld 1991).

\section{EFFECTS OF NB-DNJ IN MOUSE MODEL OF SANDHOFF DISEASE}

The mouse model of Sandhoff disease was generated through the targeted disruption of the Hexb gene and lacks hexosaminidase A and B isoenzymes, resulting in the storage of GM2- and GA2-gangliosides in the CNS and periphery (Sango et al 1995). The Sandhoff disease mouse has very low levels of residual enzyme activity, con- 
ferred by the minor hexosaminidase $\mathrm{S}(\alpha \alpha)$ isoenzyme. The mice undergo rapid, progressive neurodegeneration and die at 4-5 months of age (Sango et al 1995). When Sandhoff mice were treated with NB-DNJ, their life expectancy was increased by $40 \%$ and GSL storage was reduced in peripheral tissues and in the CNS (Jeyakumar et al 1999). Following the onset of symptoms, the rate of decline was significantly different in untreated and NB-DNJ-treated mice, as was the age at which deterioration could first be detected (approximately 100 days for untreated mice and approximately 135 days for NB-DNJ-treated mice). However, the terminal stage of the disease (when the mice are moribund) was prolonged in NB-DNJ-treated mice. When GSL storage levels were measured in the untreated and NB-DNJ-treated Sandhoff mice at their end points (at 125 days and 170 days, respectively), the levels of GM2 and GA2 were comparable, indicating that death correlated with the same levels of GSL storage in the brains of the two groups of mice. Histological examination of the mice at 120 days showed reduced storage in the brain of NB-DNJ-treated mice. At the ultrastructural level, the neurons showed greatly reduced storage burdens. This reduction in GSL storage was even more pronounced in the liver. The liver, like other peripheral organs, is exposed to higher concentrations of NB-DNJ, whereas only about $5-10 \%$ of the concentration in the serum is detected in the cerebrospinal fluid (Platt et al 1997a).

\section{COMBINATION THERAPY IN THE SANDHOFF MOUSE}

Both NB-DNJ therapy (Jeyakumar et al 1999) and BMT (Norflus et al 1998) increase life expectancy in the Sandhoff mouse. The main factor that limits the efficacy of NB-DNJ treatment is the lack of significant residual enzyme levels in this mouse model. BMT is limited by the fact that few donor origin cells repopulate the brain. Combining these two approaches would be predicted to be complementary and potentially synergistic.

We have therefore evaluated the efficacy of combining these two therapies. Sandhoff disease mice treated with BMT and NB-DNJ survived significantly longer than those treated with BMT or NB-DNJ alone. When the mice were subdivided into two groups on the basis of their donor bone marrow-derived CNS enzyme levels, the high-enzyme group exhibited a greater degree of synergy $(25 \%)$ than did the group as a whole $(13 \%)$. Combination therapy may therefore be the strategy of choice for treating the infantile-onset disease variants (Jeyakumar et al 2001).

\section{CLINICAL EVALUATION OF SUBSTRATE DEPRIVATION THERAPY IN TYPE I GAUCHER DISEASE}

In 1998-1999 patients with nonneuronopathic Gaucher disease were recruited at four centres (Cambridge, Amsterdam, Prague and Jerusalem) into a one-year open-label clinical trial of NB-DNJ (Cox et al 2000). The trial was coordinated by Oxford GlycoSciences and NB-DNJ was referred to as OGT-918.

Twenty-eight adult patients (14 females and 14 males) were enrolled, seven of whom had had previous splenectomies. All patients were unable or unwilling to take 
enzyme replacement therapy. Liver and spleen volumes were measured by MRI or computed tomography and haematological parameters were monitored. In addition, several biochemical markers were measured, including chitotriosidase (Aerts and Hollak 1997), cell surface leukocyte GM1 as an indicator of whether GSL levels were depleted in response to OGT-918 treatment, and the plasma levels of GlcCer, the storage lipid.

Most patients were treated with oral doses of $100 \mathrm{mg}$ OGT-918 three times per day. Three patients received $200 \mathrm{mg}$ three times a day and four patients had their doses lowered to $100 \mathrm{mg}$ once or twice a day. The rationale for individualized dosing was based upon individual variation in the pharmacokinetics of the compound, tolerability and organ volume response after 6 months of treatment.

\section{Pharmacokinetics}

On the basis of the in vitro studies (Platt et al 1994a,b), normal mouse studies (Platt et al 1997b) and animal models studies (Platt et al 1997a), it was thought that a serum level in humans of 5-10 $\mu \mathrm{mol} / \mathrm{L}$ should be sufficient to partially inhibit GSL synthesis and impact the disease (Platt and Butters 1998). Pharmacokinetic profiling in a subgroup of patients showed that the drug reached maximum plasma concentrations by $2.5 \mathrm{~h}$ with a plasma half-life of $6.3 \mathrm{~h}$. Steady-state concentrations of OGT-918 were achieved by day 15 of dosing and the mean peak level of OGT-918 over the 12 -month study was $6.8 \mu \mathrm{mol} / \mathrm{L}$ with trough values of $3.9 \mu \mathrm{mol} / \mathrm{L}$ (Cox et al 2000).

\section{Side-effects}

The major known side-effect of OGT-918 is diarrhoea. This was noted in the previous trial with this compound when it was tested as an antiviral agent (Fischl et al 1994). The compound is a disaccharidase inhibitor and therefore prevents the breakdown of complex dietary carbohydrates at the intestinal brush border. Unabsorbed sugar molecules remain in the gastrointestinal tract, leading to the osmotic influx of water into the intestinal lumen and resulting in diarrhoea and flatulence due to enhanced bacterial fermentation.

In the Gaucher clinical study the dose given was tenfold lower than in the HIV trial. In the Gaucher study it was found that, although most patients reported GI tract symptoms as soon as they started taking OGT-918, the diarrhoea spontaneously resolved in most patients within several weeks and did not generally pose a significant problem (Cox et al 2000).

Of the 28 patients enrolled in the trial, 6 withdrew. Two were unable to tolerate the GI tract side-effects (one suffered from Parkinson disease and the other did a lot of business travel). Two patients withdrew owing to pre-existing medical conditions (hepatocellular carcinoma and pulmonary hypertension), one additional patient left to start a family and another was advised by her rabbi to withdraw after one day on study. The remaining 22 patients were monitored at 6 and 12 months for signs 
of clinical improvement. Two further patients withdrew because of symptoms of peripheral neuropathy. All other patients on OGT-918 have been investigated by electromyography and to date no other cases have been identified. Eighteen patients have continued to receive OGT-918 beyond the 12-month study in an extended treatment protocol, with some patients having so far taken therapy for 2.5 years.

\section{Biochemical efficacy}

One of the critical issues concerning the use of OGT-918 in man was whether GSL depletion can be achieved. The activity of NB-DNJ to inhibit GSL biosynthesis was unknown when the HIV clinical trial was conducted, so this property of the drug had never been investigated in humans prior to the Gaucher clinical trial.

GSL depletion was assessed in three different ways. First, a GSL unrelated to the disease was monitored on the cell surface of leukocytes to give a sensitive measure of general GSL depletion. This was achieved using a flow cytometric assay measuring cell surface GM1 (Platt et al 1994a). This demonstrated a 38\% reduction after 12 months of therapy (Cox et al 2000). On a small number of samples, levels of leukocyte LacCer (a lipid that contributes to the GlcCer storage burden in macrophages owing to its abundance in the cells they phagocytose) were measured by TLC and also showed a time-dependent reduction (F. Platt and T. D. Butters, unpublished data). Finally, preliminary analysis of GlcCer itself was done in the plasma of several patients and initial analysis demonstrated reduced levels following treatment (H. J. Aerts and S. van Weely, unpublished data). Taken together, these data show that, at the plasma levels achieved in the study, (a) GSL expression is reduced in accordance with the mechanisms of action of this drug; (b) LacCer in leukocytes is reduced, thereby reducing the burden of this lipid ingested by macrophages; and (c) the disease storage product (GlcCer) present in the plasma was reduced from baseline. This therefore provides the biochemical foundation for the proposed substrate deprivation mechanism central to this treatment strategy. Furthermore, when the plasma was investigated for the presence of glycosylated $N$-glycans that arise due to ER $\alpha$-glucosidase inhibition (the activity of NB-DNJ responsible for its antiviral properties), only trace levels could be detected. Therefore, as predicted from previous studies (reviewed in Platt and Butters 2000), the low dose of compound used in the Gaucher trial has little impact on the other pathway inhibited by this drug because of the inaccessibility of the $\alpha$-glucosidase- 1 enzyme target (located in the ER lumen).

\section{Clinical efficacy}

Spleen and liver volumes showed a statistically significant reduction $(15 \%$, range $11.8-18.4, p<0.001$ and $7 \%$, range 3.4-10.5, $p<0.001$, respectively) after 6 months of therapy. At 12 months the decrease from baseline was 19\% (range 14.3-23.7, 
$p<0.001$ ) and $12 \%$ (range $7.8-16.4, p<0.001$ ), respectively (Cox et al 2000). When chitotriosidase, a marker of the disease activity, was measured, the macrophage-derived enzyme showed a time-dependent reduction, indicating a reduction in the total pool of Gaucher cells within the patients treated with OGT-918 (Cox et al 2000). Haematological parameters of haemoglobin and platelet counts showed trends towards improvement, with a greater improvement in haemoglobin noted in patients who were anaemic at baseline. A statistically significant improvement in platelet counts was achieved following 12 months of treatment. Assessment of 18 patients in the extended-use protocol has shown (a) continued improvement in organ volume reduction, (b) further haematological improvements in platelets and haemoglobin (all values now statistically significant) and (c) continued decline in chitotriosidase (presented at the 4th EWEGD workshop, Jerusalem, September 2000 by Zimran et al). These data strongly indicate that GSL depletion improves all key clinical features of Gaucher disease.

\section{Kinetics of clinical improvement}

Substrate deprivation therapy was predicted to be slower in its effects than enzyme replacement therapy owing to the different mechanisms of action of these two agents. Indeed, this was the rationale for choosing an initial 12-month trial period. In Gaucher disease the main pathology is the result of Gaucher cells, which are macrophages engorged with GlcCer. Although the enzyme deficiency is present in every cell type, the manifestations are restricted to professional phagocytes. The reason for this is that reduced glucocerebrosidase activity in nonphagocytes is tolerated as more enzyme is expressed in the lysosome than is needed to cope with the normal turnover of endogenous GSLs in the cell. However, in the case of the macrophage, the residual enzyme cannot cope with the burden of GSLs acquired following phagocytosis of apoptotic leukocytes and senescent red blood cells. Hence, the storage occurs selectively in macrophages, leading to their activation and the resultant pathology. If substrate deprivation is to work it therefore requires that leukocytes and red cells are produced in the bone marrow in the presence of NB-DNJ to inhibit GSL biosynthesis, thus lowering their GSL content. When these cells are finally ingested by macrophages, the GSL burden entering the phagolysosome will be decreased. As the life-span of the cells in questions is in the range of several weeks to months, we expected that the response to OGT-918 would be slower than that observed with enzyme replacement. This was borne out in particular by the slower rate of haematological improvement and the slightly slower reduction in organ volumes and plasma chitotriosidase activity. It is interesting that the decrease in organ volumes occurred more rapidly than the haematological improvement. The reasons for this are not yet known. However, in the analysis of the data from the Gaucher registry, analysing data from over 700 Gaucher patients, it was found that the degree of splenomegaly did not correlate with the degree of cytopenia. These two events are therefore not directly coupled (Scott et al 2000). The rate of response to NB-DNJ therapy also suggests 
that the pathological effects of storage are not the same in all sites of disease. It appears that reduction in the influx of GSLs into macrophages of spleen and Kupffer cells in liver is more rapidly affected than it is in bone marrow. As the precise sites of apoptotic cell clearance and the nature of the cells being phagocytosed in the different sites are still under active investigation, the cause of the differential responses must remain speculative. However, the turnover rates of cells in the bloodstream differ greatly and they may well have preferential sites of individual clearance.

One of the clear predictions of the model proposed by Conzelmann and Sandhoff (1983) was that small differences in residual enzyme activity would make a big impact on storage. Substrate deprivation lowers substrate influx into the lysosome, allowing the residual enzyme to degrade newly incoming glycolipid and ultimately clear the stored material. Patients who have taken many years to develop symptoms (typical type I Gaucher patients) are storing GSL very slowly at the onset of disease, implying that they are only just below the critical threshold of residual enzyme required to escape pathology. A very small shift in synthetic rates of GSLs in these individuals would be predicted to allow residual enzyme to catabolize the storage material in the same way that enzyme replacement does. In this case, however, the enzyme is already in the lysosome and can therefore efficiently start degrading stored glycolipid. The probable difference in the kinetics of visceral disease improvement (as judged by changes in organ volume) and improved bone marrow function (as judged in part by haematological changes) may reflect the different cellular sources of stored GSL. For instance, T cells are known to die in the liver either by homing to the liver following commitment to die by apoptosis or by traficking to liver, where the death pathway is initiated (Crispe and Mehal 1996). There is a degree of controversy about where cells of different lineages die and how they are recognized and phagocytosed. Bone marrow phagocytes probably deal with clearance of cells that die in situ, whereas the liver serves as a major clearance site for peripheral T cells (Crispe and Mehal 19996). The spleen is likely to be the site of clearance of senescent platelets, other leukocytes and red cells. As the rates of phagocytosis (i.e. the number of cells phagocytosed per macrophage per day, and therefore the phagocytic GSL burden) and the half-lives of the various circulating cell types are different, it is not surprising that there is a hierarchy of organ involvement and response to therapy. Clearly, enzyme replacement will impact all of these simultaneously as the only prerequisite is that macrophages in different sites are all accessible to enzyme and that sufficient is delivered to the lysosome. In the case of substrate deprivation, many unknown factors could influence the rate of clinical improvement in a given organ including (a) rate of phagocytosis in the organ, (b) lineage of phagocytosed cells, (c) half-life of phagocytosed cells, (d) glycolipid content of phagocytosed cell(s) and (e) heterogeneity of the lipid components and their individual contributions to the pathological cascade that is responsible for the complex manifestations of Gaucher disease. A viable mouse model of Gaucher disease would greatly facilitate the investigation of these questions and assist our understanding of the pathogenesis of Gaucher disease. 


\section{PROSPECTS FOR COMBINATION THERAPY IN GAUCHER DISEASE}

In principle, it would be predicted that, in just the same way that BMT and substrate deprivation are synergistic in their action in the Sandhoff mouse model (Jeyakumar et al 2001), combining intravenous enzyme replacement and substrate deprivation in Gaucher patients would be a rational treatment option. Multiple permutations could be envisaged, including monotherapy, sequential therapy (i.e. enzyme followed by NB-DNJ maintenance) or co-administration (i.e. continuous NB-DNJ with periodic enzyme administration). One issue that would restrict direct co-administration would be inhibition of glucocerebrosidase by NB-DNJ, as this compound is a known inhibitor of this enzyme. The $\mathrm{IC}_{50}$ value for $\beta$-glucocerebrosidase inhibition is $520 \mu \mathrm{mol} / \mathrm{L}$ which is 25 times higher than that required to inhibit the ceramide-specific glucosyltransferase ( $\left.\mathrm{IC}_{50} 20 \mu \mathrm{mol} / \mathrm{L}\right)(\mathrm{Platt}$ et al 1994b). Therefore, in the presence of a serum concentration of NB-DNJ of 5-50 $\mu \mathrm{mol} / \mathrm{L}, \mathrm{NB}-\mathrm{DNJ}$ will inhibit GSL biosynthesis but not cause inhibition of glucocerebrosidase (Platt et al 1994b). This has now been demonstrated in vivo in healthy mice. When mice were treated with NB-DNJ $4800 \mathrm{mg} / \mathrm{kg}$ per day $(50 \mu \mathrm{mol} / \mathrm{L}$ serum level) and co-administered glucocerebrosidase $(5-10 \mathrm{U} / \mathrm{kg}$ Ceredase), no inhibition of enzyme was detected (even at inhibitor concentrations above those being achieved in the clinical studies) (Priestman et al 2000). If anything, apparent potentiation of circulating enzyme half-life was observed. This increase in circulating half-life could be due either to reduced enzyme uptake or to stabilization of the enzyme. Glucocerebrosidase is taken up via macrophage mannose receptors, which do not recognize glucose. It is therefore very unlikely that a glucose analogue such as NB-DNJ would directly bind to this receptor. However, the enzyme is unstable at neutral $\mathrm{pH}$ and is rapidly inactivated in the plasma, and it therefore seems more likely that the inhibitor stabilized the active site of the enzyme in an analogous fashion to the stabilization of $\alpha$-galactosidase by DGJ (Fan et al 1999). If enzyme half-life is extended in man, it may promote uptake over time into macrophages, as the vast majority of enzyme administered is not taken up by macrophages. Irrespective of the mechanism and whether or not enzyme potentiation is observed in man, co-administration is a viable option, as no enzyme inhibition occurs, and may increase considerably the therapeutic options for the management of this particular disease.

\section{FUTURE COMPOUNDS FOR SUBSTRATE DEPRIVATION THERAPY}

The compound NB-DGJ is a galactose analogue that is also a potent inhibitor of the ceramide glucosyltransferase (but not the galactosyltransferase important in Gal-Cer synthesis for myelin function). We have compared this analogue to NB-DNJ both in in vitro enzyme assays and also at high doses in mice to unmask potential side-effects. NB-DGJ is a more selective enzyme inhibitor with fewer complicating inhibitory properties and will be subjected to preclinical toxicological testing in the near future (Andersson et al 2000). One very important observation was made in this comparative study. It was found that none of the effects of NB-DNJ 
induced at high doses (10 times greater serum level than the clinical study), such as weight loss and lymphoid organ shrinkage (Platt et al 1997b), are attributable to GSL depletion. They must be due to other properties of NB-DNJ, since NB-DGJ lacks these effects but is an equivalent inhibitor of GSL biosynthesis in vivo (Andersson et al 2000).

It has also been shown that deoxynojirimycin with a hydrophobic adamantane group linked via a pentyl spacer is an extremely potent inhibitor of GlcCer synthesis in cultured cells $\left(\mathrm{IC}_{50}\right.$ of approximately $50 \mathrm{nmol} / \mathrm{L}$ ) (Overkleeft et al 1998). It remains unclear whether this type of very hydrophobic compound is intrinsically suited for medical applications or is only of value as a tool in the fundamental research of GSL synthesis and transport.

\section{FUTURE FOR CNS THERAPY}

The clinical study in type I Gaucher disease has provided evidence for improvement in many signs and laboratory features of the disease. An increase in therapeutic options for type I Gaucher disease could provide alternative regimes for treating patients. The fact that two therapeutic approaches (enzyme replacement and substrate deprivation) attack the disease from different mechanistic sides of the synthesis : catabolism equation should permit a whole range of treatment and management protocols to be devised and evaluated clinically.

However, the principal additional contribution that the substrate deprivation approach could make would be in the currently refractory and severe variants of Gaucher disease (types II and III), which affect the brain, and in the gangliosidosis patients who have progressive neurodegenerative disease. The preclinical studies in mouse models of Tay-Sachs and Sandhoff disease (Jeyakumar et al 1999; Platt et al 1997a) offer the prospect that these drugs may be of benefit to patients with these conditions, at least those with the juvenile- and adult-onset variants of these disorders. The intractable infantile-onset variants will undoubtedly need an additional enzyme augmenting modality if the disease is to be treated (Jeyakumar et al 2001).

With the advent of more effective means for delivering enzymes to the CNS (BMT, gene therapy and neuronal stem cell therapy), there is a real prospect that over the next decade there may be a number of strategies available for improving the lives of the patients suffering from these devastating neurological diseases.

\section{ACKNOWLEDGEMENTS}

F.M.P. is a Lister Institute Research Fellow. R.H.L. is a Wellcome Trust Clinician Scientist Fellow.

\section{REFERENCES}

Aerts JM, Hollak CE (1997) Plasma and metabolic abnormalities in Gaucher's disease. Baillières Clin Haematol 10: 691-709. 
Andersson U, Butters TD, Dwek RA, Platt FM (2000) $N$-butyldeoxygalactonojirimycin; a more selective inhibitor of glycosphingolipid biosynthesis than $N$-butyldeoxynojirimycin, in vitro and in vivo. J Biochem Pharmacol 56: 421-430.

Chavany C, Jendoubi M (1990) Biology and potential strategies for the treatment of G(M2) gangliosides. Mol Med Today 4: 158-165.

Conzelmann E, Sandhoff K (1983) Partial enzyme deficiencies: residual activities and the development of neurological disorders. Dev Neurosci 6: 58-71.

Cox T, Lachmann R, Hollak C, et al (2000) Novel oral treatment of Gaucher's disease with $N$-butyldeoxynojirimycin (OGT 918) to decrease substrate biosynthesis. Lancet 355: 1481-1485.

Crispe IN, Mehal WZ (1996) Strange brew: T cells in the liver. Immunol Today 17: 522-525.

Eng C, Phelps R, Kim L (2000) Enzyme replacement therapy for Fabry disease. J Inherit Metab Dis 23 (supplement 1): 222.

Erikson A, Groth CG, Mansson JE, Percy A, Ringden O, Svennerholm L (1990) Clinical and biochemical outcome of marrow transplantation for Gaucher disease of the Norrbottnian type. Acta Paediatr Scand 79: 680-685.

Erikson A, Bembi B, Schiffmann R (1997) Neuronopathic forms of Gaucher's disease. Baillières Clin Haematol 10: 711-723.

Fan JQ, Ishii S, Asano N, Suzuki Y (1999) Accelerated transport and maturation of lysosomal alpha-galactosidase A in Fabry lymphoblasts by an enzyme inhibitor. Nature Medicine $\mathbf{5}$ : $112-115$.

Fischl MA, Resnick L, Coombs R, et al (1994) The safety and efficacy of combination $N$-butyl-deoxynojirimycin (SC-48334) and zidovudine in patients with HIV-1 infection and 200-500 CD4 cells $/ \mathrm{mm}^{3}$. J Acquir Immune Defic Syndr 7: 139-147.

Inokuchi J-I, Radin NS (1987) Preparation of the active isomer of 1-phenyl-2-decanoylamino-3-morpholino-1-propanol, inhibitor of murine glucocerebroside synthetase. J Lipid Res 28: 565-571.

Jeyakumar M, Butters TD, Cortina-Borja M et al (1999) Delayed symptom onset and increased life expectancy in Sandhoff disease mice treated with $N$-butyldeoxynojirimycin. Proc Natl Acad Sci USA 96: 6388-6393.

Jeyakumar M, Norflus F, Tifft CJ, et al (2001) Enhanced survival in Sandhoff disease mice receiving a combination of substrate deprivation therapy and bone marrow transplantation. Blood 97: 327-329.

Krivit W, Sung JH, Shapiro EG, Lockman LA (1995) Microglia: the effector cell for reconstitution of the central nervous system following bone marrow transplantation for lysosomal and peroxisomal storage diseases. Cell Transplant 4, 385-392.

Marshall E (1999) Gene therapy death prompts review of adenovirus vector [news]. Science 286: 2244-2245.

Meikle PJ, Hopwood JJ, Clague AE, Carey WF (1999) Prevalence of lysosomal storage disorders. J Am Med Assoc 281: 249-254.

Moran MT, Schofield JP, Hayman AR, Shi G-P, Young E, Cox TM (2000) Pathologic gene expression in Gaucher disease: up-regulation of cysteine proteinases including osteoclastic cathepsin K. Blood 96: 1969-1978.

Neufeld EF (1991) Lysosomal storage diseases. Annu Rev Biochem 60: 257-280.

Norflus F, Tifft CJ, McDonald MP, et al (1998) Bone marrow transplantation prolongs life span and ameliorates neurologic manifestations in Sandhoff disease mice. J Clin Invest 101: 1881-1888.

Overkleeft HS, Renkema GH, Neele J, et al (1998) Generation of specific deoxynojirimycin-type inhibitors of the non-lysosomal glucosylceramidase. $J$ Biol Chem 273: 26522-26527.

Peng KW (1999) Strategies for targeting therapeutic gene delivery. Mol Med Today 5: 448-453.

Phaneuf D, Wakamatsu N, Huang JQ et al (1996) Dramatically different phenotypes in mouse models of human Tay-Sachs and Sandhoff diseases. Hum Mol Genet 5: 1-14. 
Platt FM, Butters TD (1995) Inhibitors of glycosphingolipid biosynthesis. Trends Glycosci Glycotechnol 7: 495-511.

Platt FM, Butters TD (1998) New therapeutic prospects for the glycosphingolipid lysosomal storage diseases. Biochem Pharmacol 56: 421-430.

Platt FM, Butters TD (2000) Substrate deprivation: a new therapeutic approach for the glycosphingolipid lysosomal storage diseases. Expert Reviews in Molecular Medicine. 〈http://www-ermm.cbcu.cam.ac.uk〉

Platt FM, Karlsson GB, Jacob GS (1992) Modulation of cell-surface transferrin receptor by the imino sugar $N$-butyldeoxynojirimycin. Eur J Biochem 208: 187-193.

Platt FM, Neises GR, Dwek RA, Butters TD (1994a) $N$-Butyldeoxynojirimycin is a novel inhibitor of glycolipid biosynthesis. J Biol Chem 269: 8362-8365.

Platt FM, Neises GR, Karlsson GB, Dwek RA, Butters TD (1994b) $N$-Butyldeoxygalactonojirimycin inhibits glycolipid biosynthesis but does not affect $N$-linked oligosaccharide processing. J Biol Chem 269: 27108-27114.

Platt FM, Neises GR, Reinkensmeier G, et al (1997a) Prevention of lysosomal storage in Tay-Sachs mice treated with $N$-butyldeoxynojirimycin. Science 276: 428-431.

Platt FM, Reinkensmeier G, Dwek RA, Butters TD (1997b) Extensive glycosphingolipid depletion in the liver and lymphoid organs of mice treated with $N$-butyldeoxynojirimycin. J Biol Chem 272: 19365-19372.

Priestman DA, Platt FM, Dwek RA, Butters TD (2000) Imino sugar therapy for type 1 Gaucher disease. Glycobiology 10, iv-vi.

Radin NS (1996) Treatment of Gaucher disease with an enzyme inhibitor. Glycoconj J 13: 153-157.

Ringden O, Groth CG, Erikson A, Granqvist S, Mansson JE, Sparrelid E (1995) Ten years' experience of bone marrow transplantation for Gaucher disease. Transplantation 59: 864-870.

Romano G, Pacilio C, Giordano A (1999) Gene transfer technology in therapy: current applications and future goals. Stem Cells 17: 191-202.

Sango K, Yamanaka S, Hoffmann A, et al (1995) Mouse models of Tay-Sachs and Sandhoff diseases differ in neurologic phenotype and ganglioside metabolism. Nature Genetics 11: $170-176$.

Scott CR, Andersson H, Charrow J et al (2000) The impact of genotype on clinical expression of Gaucher disease: data from 733 patients. J Inherit Metab Dis 23 (Suppl 1): 226.

SoRelle R (2000) Gene therapy at a crossroads [news]. Circulation 101: E9001.

Suzuki K, Mansson J-E. (1998) Animal models of lysosomal disease: an overview. J Inherit Metab Dis 21: 540-547.

Suzuki K, Proia RL (1998) Mouse models of human lysosomal diseases. Brain Pathol 8: 195-215

Svendsen CN, Caldwell MA, Ostenfeld T (1999) Human neural stem cells: isolation, expansion and transplantation. Brain Pathol 9 499-513.

Taniike M, Yamanaka S, Proia RL, Langaman C, Bone Turrentine T, Suzuki K (1995) Neuropathology of mice with targeted disruption of Hexa gene, a model of Tay-Sachs disease. Acta Neuropathol Berl 89: 296-304.

Van den Hout JMP, Reuzer AJJ, de Klerk JBC, Arts WF, Smeitink JAM, van der Ploeg AT (2001) Enzyme therapy for Pompe's disease with recombinant human $\alpha$-glucosidase from rabbit milk. J Inherit Metab Dis 24: 266-274.

Vescovi AL, Snyder EY (1999) Establishment and properties of neural stem cell clones: plasticity in vitro and in vivo. Brain Pathol 9: 569-598.

Walkley SU (1998) Cellular pathology of lysosomal storage disorders. Brain Pathol 8: 175-193.

Yamanaka S, Johnson MD, Grinberg A, et al (1994) Targeted disruption of the Hexa gene results in mice with biochemical and pathologic features of Tay-Sachs disease. Proc Natl Acad Sci USA 91: 9975-9979. 